\title{
Conformación geo-histórica de las actividades económicas en el Estado de Guerrero, México
}

\section{Geo-Historical Conformation of Economic Activities in the State of Guerrero, Mexico}

\author{
Neftali García Castro ${ }^{1}$ \\ Universidad Autónoma de Guerrero, México
}

\begin{abstract}
Resumen
Esta investigación sintetiza una serie de acontecimientos geo-históricos en torno a la configuración económico-productiva del estado de Guerrero. En el documento se presenta, 1) la secuencia que debe seguirse para confeccionar una matriz con los sucesos relevantes para un análisis desde la óptica geo-histórica, 2) paralelamente, se apuntan las razones fundamentales que soportan la selección de este enfoque y la solución metodológica propuesta, y 3) se revelan las etapas históricas con base en la forma de ocupación económica preponderante del territorio guerrerense. Lo anterior dio pauta para comprender porque ha tenido lugar el surgimiento de un número reducido asentamientos humanos considerados estratégicos para la estructuración territorial, pero con escasos efectos dinamizadores sobre espacios adyacentes.
\end{abstract}

Palabras clave: actividades económicas, cartografía, geo-histórico, Guerrero, México.

\section{Abstract}

This research synthesizes a series of geo-historical events around the economic-productive configuration of the state of Guerrero. This document presents the following: 1) the sequence that must

1 Doctor en Geografía por la Universidad Nacional Autónoma de México. Joven investigador del Programa de Cátedras CONACYT, comisionado como Profesor-investigador en la Maestría en Ciencias: Territorio y Sustentabilidad Social, programa adscrito al Centro de Investigación y Posgrado en Estudios Socioterritoriales de la Universidad Autónoma de Guerrero. 16 de septiembre núm. 42, Barrio de San Mateo, Chilpancingo, Guerrero. c.p.39000. Correo electrónico: ngarciaca@conacyt.mx 
be followed to prepare a matrix with the relevant events for an analysis from the geo-historical point of view; 2) at the same time, the document addresses the fundamental reasons that support the selection of this approach and the methodological solution proposed; and 3) it shows the historical stages based on the preponderant economic form of occupation of the territory of Guerrero. The above gave a guideline to understand why the emergence of a reduced number of settlements, considered strategic for the territorial structuring, has taken place, but with little dynamizing effects on adjacent spaces.

Keywords: economic activities, cartography, geo-historical, Guerrero, Mexico.

\section{Introducción}

La evolución geo-histórica del estado de Guerrero ha dado un carácter peculiar a esta entidad de la República Mexicana: las regiones guerrerenses son biodiversas y cuentan con patrimonio histórico-etnográfico-cultural que les confiere un lugar significativo dentro de la vida nacional. No obstante, pocos municipios, entre ellos Acapulco, Iguala, Chilpancingo, Zihuatanejo y Taxco; detentan la mayor parte de la población estatal, inversiones económicas y actividades productivas.

De acuerdo con el Instituto Nacional de Estadística y Geografía (INEGI), las cabeceras municipales de esas cinco demarcaciones se han erigido como los núcleos urbanos más importantes del estado, en conjunto albergan 1098823 personas (32.4\% del total estatal censado en 2010) (INEGI, 2017). Esas ciudades son las más atractivas para el resto de los guerrerenses, quienes migran a esos sitios y suelen emplearse, sobre todo, en trabajos relacionados con el comercio o los servicios.

En ese orden de ideas, la presente investigación tiene como objetivo central exponer cómo el territorio guerrerense advierte la impronta de etapas geo-históricas producto de la utilización económica de segmentos concretos de la entidad, en esta investigación se concibe que esto ha dado pauta para el surgimiento de un número reducido asentamientos humanos considerados estratégicos para la estructuración territorial, pero con escasos efectos dinamizadores sobre espacios adyacentes.

Las investigaciones relacionadas con tal objetivo investigativo son escasas; el trabajo de Garza (2009) hace énfasis en el origen histórico de la ausencia de vías de comunicación y del incipiente sistema urbano actual del estado. Señala que esto es resultado de las características físicas del territorio y de aspectos socioeconómicos, políticos y culturales que 
apuntalaron su posición marginal en la dinámica económico-productiva nacional e internacional.

En el artículo titulado "Los centros de comercio en el estado de Guerrero", Juárez (1998) analiza la dinámica temporal y el conjunto de factores que influyen en el establecimiento y organización de la actividad comercial en las principales ciudades de la entidad. Se identifica el surgimiento de aquellas localidades consideradas estratégicas para las transacciones realizadas en distintas regiones del estado, así como la expansión demográfica derivada de la actividad comercial, ya que ésta se concibe como configuradora del espacio; por tanto, incide sobre el funcionamiento, organización y estructura de un lugar determinado (Ibid.).

Por su parte, Ortiz (1998) muestra la distribución espacial de los guerrerenses en 1990, la importancia demográfica de los asentamientos urbanos y la dispersión de los habitantes en la superficie estatal. La investigación es producto del procesamiento de información cuantitativa recopilada tanto el XI Censo de Población como en la carta topográfica a escala 1:50 000 de INEGI. Con base en esto, se clasifica a las localidades según la cantidad de personas que la habitan y se exponen las diferencias que existen a nivel municipal y regional.

Lo puntualizado en los párrafos anteriores permite advertir porque es indispensable una investigación que brinde más elementos cognoscitivos para entender las causas fundamentales del panorama socio-territorial complejo de Guerrero, ya que éste demanda reflexiones consistentes en torno al impacto regional que tiene la incorporación heterogénea de espacios guerrerenses a la vida económica estatal, nacional e internacional.

\section{Marco metodológico-conceptual}

Para examinar las transformaciones acaecidas en el uso económico de los espacios guerrerenses, se propone una solución metodológica denominada matriz geo-histórica; la cual está comprendida dentro de los métodos de clasificación que centran la atención sobre lo cualitativo, por encima de la dimensión cuantitativa de lo estudiado (Propin, 2003). Se optó por la elaboración de una matriz de ese tipo debido a los criterios que se puntualizan enseguida: 
1. Se considera que proporciona un enfoque alternativo para el estudio del tema que se aborda en este documento, también se valoró su utilidad como medio investigativo que regule la sistematización, generalización y codificación de aquellos conocimientos que pueden plasmarse en forma escrita y cartográfica (Ibid.).

2. El análisis geo-histórico “... consiste en asegurar, interrogando el agenciamiento temporal de las sociedades, que ha ocurrido en esa región (provisionalmente delimitada por la definición convencional) un cierto número de bifurcaciones mayores que han conducido a una diferenciación y a una especificidad significativa con relación a otras regiones del mundo" (Levy, 1997: 27).

3. La geo-historia implica “... ubicar los problemas humanos tales que sean colocados en el espacio, en lo posible cartografiados, una geografía humana inteligente... que los ubique en el espacio teniendo en cuenta el tiempo: desatar la geografía de esta búsqueda de realidades actuales a las que ella se aplica exclusivamente, para repensar, con sus métodos, las realidades pasadas" (Braudel, 1982: 92)².

De esta manera, en la presente investigación, el trabajo de sistematización, generalización y codificación de la información documental gravita en torno a tres dimensiones básicas: la espacial, la temporal y la fenomenológica (Propin, op. cit.). La primera es entendida como una constante en lo vinculado con la delimitación territorial del estado de Guerrero y una variable, al considerar la localización de todos aquellos acontecimientos geo-históricos que tuvieron una impronta en la distribución de las actividades productivas guerrerenses y su concentración en determinadas áreas.

En tanto, la dimensión temporal y la fenomenológica son variables que se integran directamente en la matriz, mediante el registro de las fechas y la descripción generalizada del tipo de sucesos señalados arriba (Cuadro 1). La matriz geo-histórica compendia los aportes hechos por múltiples autores; por lo tanto, es importante incorporar las referencias bibliográficas de cada registro, esto agiliza la elaboración de reflexiones escritas sobre

2 La investigación de Aponte (2006), titulada La geo-historia, un enfoque para el estudio del espacio venezolano desde una perspectiva interdisciplinaria, constituye un referente conceptual y metodológico para los estudiosos del territorio desde la óptica espacio-tiempo. En México hay cartografía con la conformación geo-histórica de la península de Baja California (Aguilar, 2013), Coahuila (Miranda, 2011) y Guanajuato (García, 2007). 
las fases asociadas con la utilización económica de ciertos segmentos de la superficie estatal.

Cuadro1. Ejemplo de la información que se incorpora en una matriz geo-histórica

\begin{tabular}{|l|l|}
\hline Referencias temporales & \multicolumn{1}{c|}{ Acontecimientos territoriales } \\
\hline 1522 & $\begin{array}{l}\text { Fundación de Villa de San Luis debido a la extracción de oro } \\
\text { de placer en el oriente de la Costa Chica (Rubí y Pavía, 1998) }\end{array}$ \\
\hline Inicios del siglo XVIII & $\begin{array}{l}\text { La Tierra Caliente registra afluencia de ibéricos atraídos por } \\
\text { los yacimientos de Tetela y las tierras aptas para actividades } \\
\text { agropecuarias (Ibid.). }\end{array}$ \\
\hline Mediados del siglo XX & $\begin{array}{l}\text { La actividad turística de Acapulco demanda una cantidad } \\
\text { significativa de mano de obra, se origina la llegada de } \\
\text { trabajadores de otras regiones (Ramírez, 1986). }\end{array}$ \\
\hline
\end{tabular}

Fuente: elaborado con base en Ramírez, op. cit.; Rubí y Pavía, op. cit.

El tipo y la cantidad de información de la matriz es propicia para elaborar material cartográfico, ya que se identifican sitios específicos que pueden representarse con símbolos puntuales y/o evidentes; los acontecimientos que tuvieron expresión dispersa en un territorio, o bien de los que se tiene una referencia espacial vaga, se plasman con métodos de área; y las líneas de movimiento facilitan la representación de información relacionada con el movimiento de población, materias primas, productos, etc.

Propin (op . cit.) apunta que esta cartografía constituye una forma de aprensión del conocimiento revelado y, por lo tanto, es síntesis del proceso de investigación expuesto de manera estructural a través de métodos de representación cartográfica. Estos mapas, con tres o más capas de información, pueden ser calificados como cargados. Sin embargo, “... el éxito comunicativo de este tipo de mapa final se centra en la estructuración clara de la leyenda, debido a su extensión y complejidad temática" (Ibid.: 93).

\section{Características geográficas del estado de guerrero}

Guerrero se ubica al sur de la República Mexicana. Ocupa el décimo cuarto lugar por su extensión territorial a nivel nacional, esto es 63 $794 \mathrm{~km}^{2}$ (3.2\% del área total del país). La división político-administrativa vigente estaba conformada por ochenta y un municipios (INEGI, op. cit.) (Figura 1). La entidad se divide en las regiones siguientes: Norte, Centro, 
Acapulco, Tierra Caliente, Montaña, Costa Grande y Costa Chica. La Montaña concentra el mayor número de municipios, diecinueve en total.

Del total de guerrerenses, $23 \%$ reside en el municipio de Acapulco (810 669 habitantes), 8\% en Chilpancingo (273 106 habitantes), 4.3\% en Iguala (151 660 habitantes), 3.7\% en Chilapa (129 867 habitantes), 3.5\% en Zihuatanejo de Azueta (124 824 habitantes), 3.1\% en Taxco (108 416 habitantes), $2.5 \%$ en Tlapa (87 967 habitantes) y $2.1 \%$ en Coyuca de Benítez (76 306 habitantes). La población restante se distribuye en los otros 73 municipios de la entidad, de los cuales 54 no rebasan, individualmente, $1 \%$ del total de guerrerenses (Ibid.).

Figura 1. Guerrero: división político-administrativa

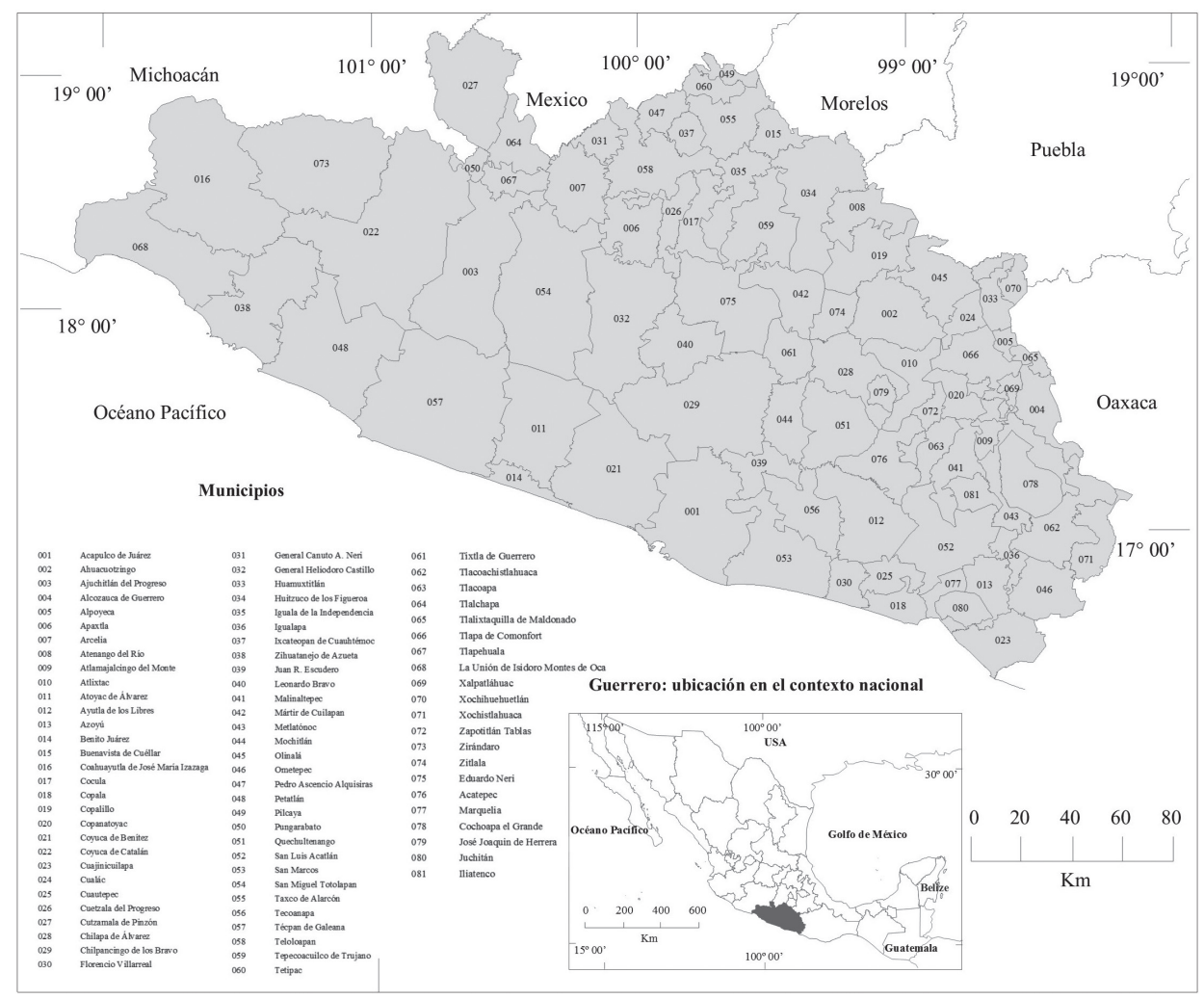

Fuente: elaborado con base en INEGI, op. cit. 
La Montaña, la Costa Chica y la región Centro constituyen las áreas con presencia sobresaliente de población indígena. En 2010, ésta sumó 475099 personas, 7\% del total nacional. El 36\% de ellos pertenece al grupo nahua, $29 \%$ son mixtecos, $25 \%$ tlapanecos y $9 \%$ amuzgos (Ibid.). Por lo general, al igual que otras entidades mexicanas, la población indígena guerrerense habita en localidades dispersas, carentes de infraestructura básica y escasamente articuladas.

La población originaria es numerosa en los municipios de Cochoapa el Grande, Metlatónoc, Atlamajalcingo del Monte, Acatepec Tlacoapa, Iliatenco, Zapotitlán Tablas, Malinaltepec, Xalpatláhuac, Copalillo, Copanatoyac Xochistlahuaca, José Joaquin de Herrera, Alcozauca de Guerrero, Tlacoachistlahuaca, en estas demarcaciones representa más del $90 \%$ del total municipal.

En la entidad, sólo unos cuantos municipios han recibido impulso federal, estatal y del capital privado, relacionado con actividades como el turismo, la minería o las agroindustrias, entre ellos Acapulco, Iguala, Zihuatanejo de Azueta, Taxco y Zumpango del Río. Asimismo, hay pocos espacios que deben su relevancia territorial a la función político-administrativa (Chilpancingo) o a que, además, han desempeñado un papel fundamental en el abastecimiento regional de bienes y servicios (Tixtla, Tlapa, Arcelia, Teloloapan, Atoyac de Álvarez, Petatlán) (García, 2011).

De acuerdo con el Consejo Nacional de Evaluación de la Política de Desarrollo Social (CONEVAL), en Guerrero hay 1112000 personas en situación de pobreza extrema, esto es $31.7 \%$ de los guerrerenses. En la entidad, $78.5 \%$ de los habitantes tiene carencias vinculadas con el acceso a la seguridad social; 59\%, asociadas con los servicios básicos en sus viviendas; $39.4 \%$, ligadas con el acceso a la alimentación; 33.4\%, relacionadas con la calidad y dimensiones de la vivienda; $26.8 \%$ presenta rezago educativo y $25.4 \%$ muestra deficiencias en el acceso a los servicios de salud (CONEVAL, 2017).

El estado ha mostrado un éxodo de campesinos que buscan mejores ingresos en las ciudades de Guerrero, en otras entidades federativas o en Estados Unidos. Cada año, casi, 73000 guerrerenses se desplazan a Oregón, California, Arizona, Mississippi, Florida, Nueva York, Virginia o Carolina del Norte. También, cada verano, cerca de 128000 jornaleros del estado emigran para laborar en los campos agrícolas de Sonora, 
Chihuahua, Baja California o Sinaloa. Así, el territorio guerrerense se ha posicionado entre las cinco entidades de la República Mexicana que presentan mayor emigración (INEGI, op. cit.).

\section{Conformación geo-histórica}

La configuración económica del estado de Guerrero es resultado de factores socio-territoriales vigentes y la influencia de sucesos geo-históricos. En este sentido, “... uno de los problemas fundamentales inherente a cualquier estudio sistemático de la organización del espacio es determinar porque cada cosa está situada en un determinado lugar en vez de en otro cualquiera" (Santos, 1979: 42). Por esa razón, a continuación se exponen los rasgos sobresalientes de la evolución geo-histórica guerrerense.

\section{Génesis de la diversidad cultural (antes de 1519)}

Hace más de 10000 años, el actual estado de Guerrero era recorrido por nómadas; la porción noreste y más tarde los valles centrales y La Montaña. Los primeros asentamientos humanos surgieron entre los años 5 000 y 1200 a. C., ubicados cerca de los ríos y cuerpos de agua. Ese fue el caso de los actuales Puerto Marqués, Coyuca de Benítez y San Jerónimo fundados en la costa, área donde se comenzó a practicar una agricultura primitiva (Serra-Puche, 1990 citada por Juárez, op. cit.) (Figura 2).

Entre los años 1200 y 500 a. C., el territorio estuvo ocupado por grupos relacionados con la cultura olmeca; ésta tuvo presencia en la cuenca del río Balsas y sus alrededores, hasta el año 500 a. C., fecha en la que en Mesoamérica se pierde su influencia y cobran importancia otras etnias a nivel local y regional (Reyna, 2009). Fue el caso de los mezcala que se erigieron como el grupo cultural preponderante en las márgenes del río del mismo nombre y, gradualmente, se propagó hacia la Costa, la Tierra Caliente y las Sierras de Norte, así como a Centro y Suramérica, a través del comercio. 
Neftali García Castro. Conformación geo-histórica de las actividades económicas en el Estado de Guerrero, México

Figura 2. Guerrero: características socio-económicas antes de 1519

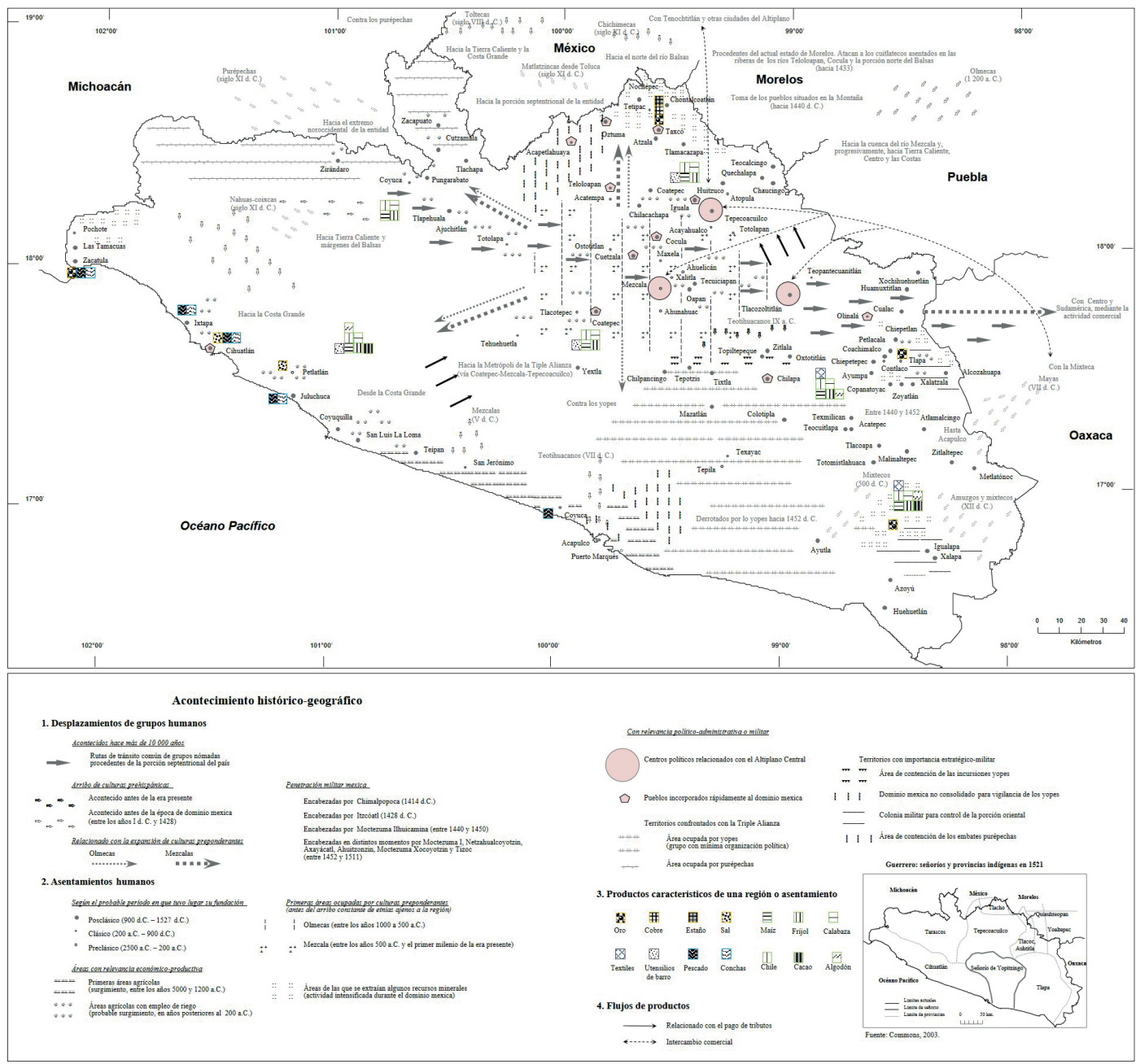

Fuente: elaborado con base en Commons, 1985; Gerhard, 1986; Secretaría de Gobernación, 1988; Juárez, op. cit.; Illades, 2000; Garza, op. cit.; Reyna, op. cit.

A principios de esta era, el desarrollo alcanzado por las civilizaciones que habitaban en el centro y sureste de Mesoamérica dio pauta para que incrementaran su intercambio comercial y cultural con sitios distantes. Así, arribaron, a lo que hoy es el territorio guerrerense, teotihuacanos, toltecas, purépechas, mixtecos, mayas y zapotecos que aportaron elementos culturales a los mezcala (Secretaría de Gobernación, 1988). 
Para el siglo XIV, la Tierra Caliente estaba habitada por purépechas, cuitlatecas, ocuitecas y matlatzincas; la sierra del Norte por chontales, mazatlecos y tlahuicas; los valles Centrales por coixcas y tepoztecos; La Montaña por tlapanecos y mixtecos; la Costa Chica por yopes, mixtecos y amuzgos y la Costa Grande por tolimecas, chubias, pantecas y cuitlecas (Commons, 1985).

Entre 1485-1502, la mayor parte del territorio guerrerense quedó bajo el control del imperio azteca. Éste, por cuestiones tributarias y de dominio militar, se dividió en las provincias siguiente: Taxco, Tepecoacuilco; Cihuatlán, Tlapa, Tlacozauhtitlán, Quiauhteopan e Igualtepec (Gerhard, 1986). Sólo la región yope, situada al oeste de la Costa Chica, y el área occidental purépecha no quedaron bajo el dominio azteca.

En la mayoría de esas provincias, se sembraba maíz, fríjol, calabaza, chile, cacao y algodón. Únicamente en la cuenca del Balsas y en la Costa se cultivaba con riego, una situación que posibilitó que se tributaran volúmenes considerables de productos agrícolas, al imperio azteca. Además, se enviaban tejidos de algodón, copal, barniz amarillo, utensilios de barro, tecomates, jícaras, hachuelas de cobres, conchas marinas, turquesas y oro, este último extraído, principalmente, de los ríos de la Costa Chica y en el extremo occidental de la Costa Grande (Illades, 2000).

Desde el período olmeca, los poblados con relevancia político-económica se situaron a lo largo de la cuenca media del río Balsas, cobraron relevancia Xochipala, Teopantecuanitlan, Tlalcozauhtitlan o Mezcala. De la misma forma, durante el dominio azteca, Tepecoacuilco se consolidó como núcleo interregional, pues mantuvo contacto no sólo con Tenochtitlán y sus dominios al suroeste, sino también con las tierras mixtecas (Garza, op. cit.). El resto de los poblados se caracterizaban por sostener, fundamentalmente, un intercambio interno tanto de productos agrícolas como de aquellos derivados de la recolección, la caza o pesca.

\section{Los incipientes asentamientos hispanos (1519-1700)}

En lo que hoy conforma al estado de Guerrero, las primeras incursiones de los conquistadores españoles acontecieron entre noviembre de 1519 y agosto de 1521. Los dos primeros siglos de dominio español se caracterizaron por la existencia de asentamientos hispanos efímeros. La fundación de los pueblos fue impulsada por el descubrimiento de oro, plata 
u otros metales ${ }^{3}$. La mayoría de las ocasiones, una vez que se terminaban esos recursos, sus habitantes emigraban (Rubí y Pavía, op. cit.) (Figura 3). En términos generales, los conquistadores se asentaron en la porción centro-norte y en la costa guerrerense. Es en esta última donde se introdujeron, tempranamente, las actividades agropecuarias. Éstas y la extracción de los recursos naturales con los que contaba el territorio demandaron esclavizar a los grupos indígenas o bien organizarlos en encomiendas y/o repartimientos (Secretaría de Gobernación, op. cit.).

3 Zumpango y Taxco atrajeron, rápidamente, a los españoles. Los yacimientos de oro y plata del primero se comenzaron a explotar a principio del decenio de 1530, su riqueza dio la pauta para que los mineros solicitaran, a las autoridades españolas, la apertura de un camino para abastecerse de alimentos e insumos. En 1533, se aprobó la construcción del sendero que los comunicó con la Ciudad de México, el cual, a la postre, favoreció que la ruta entre la capital de la Nueva España y Acapulco atravesará por Zumpango y Chilpancingo (Rubí y Pavía, op. cit.). Por su parte, las vetas de plata taxqueñas se descubrieron hasta 1534 y registraron su primer auge hacia mediados del siglo XVI. En lo sucesivo, los significativos volúmenes de plata extraídos, apuntalarían a Taxco como uno de los principales centros económicos de esta porción del territorio novohispano (Pérez, 1996). 
Neftali García Castro. Geo-Historical Conformation of Economic Activities in the State of Guerrero, Mexico

Figura 3. Guerrero: características socio-económicas entre los siglos XVI y XVIII

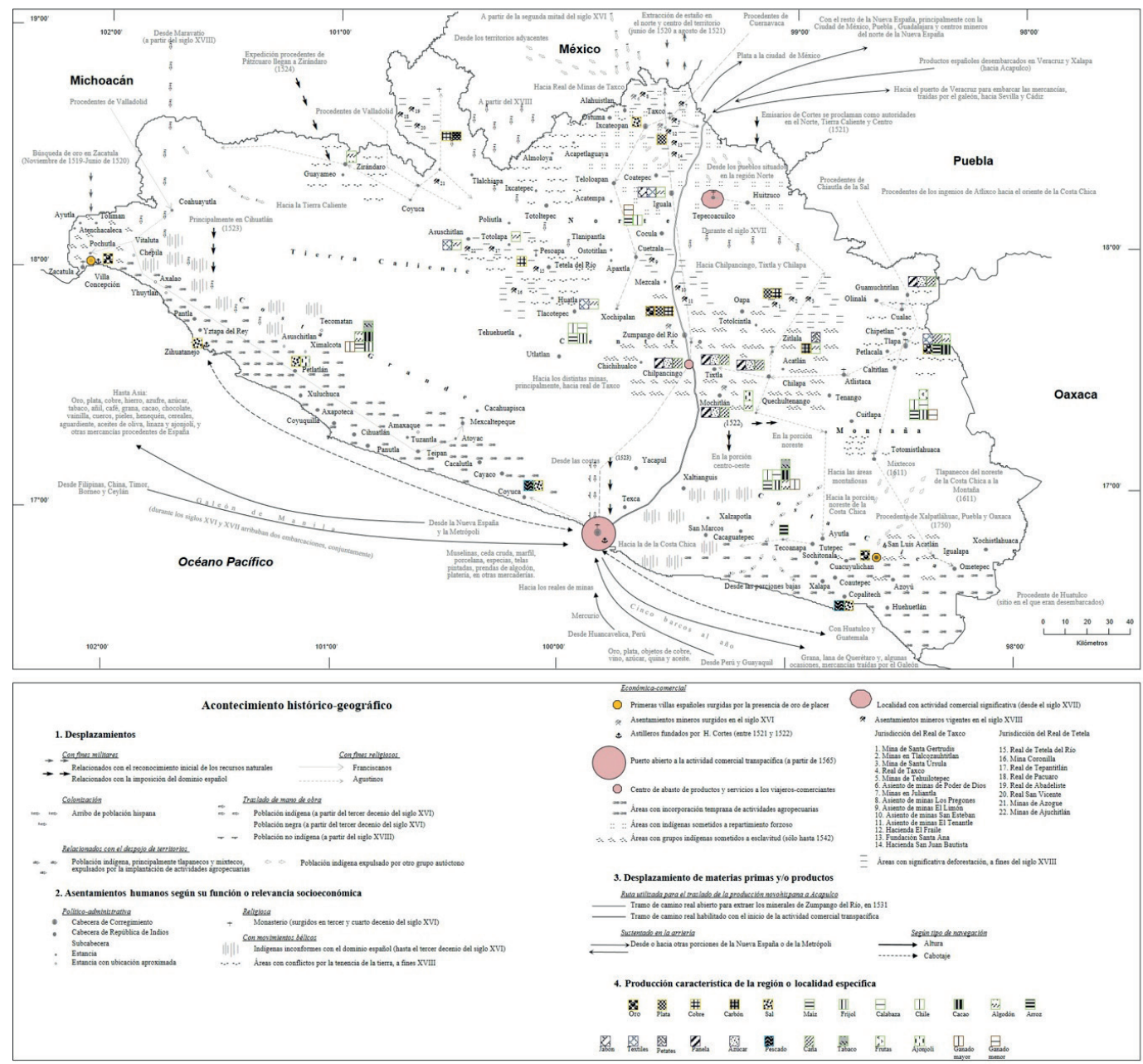

Fuente: elaborado con base en Commons, op. cit.; Gerhard, op. cit.; Secretaría de Gobernación, op. cit.; Juárez, op. cit.; Illades, op. cit.; Garza, op. cit.; Reyna, op. cit.

Lógicamente, en toda la Nueva España, se suscitó una reducción importante de la población nativa debida no sólo a la brutalidad con la que era tratada, en algunas ocasiones; sino también a las enfermedades traídas por los españoles (Illades, op. cit.). La mano de obra indígena mermó en la mayor parte del territorio guerrerense, esto provocó la introducción tanto 
de indígenas procedentes de las entidades vecinas como de esclavos africanos para continuar con las labores agropecuarias y la explotación de las minas (Quiroz, 1998).

La población indígena que subsistió continúo con la siembra de maíz, fríjol, calabaza y chile, la base de su alimentación. También tuvieron que ocuparse de las áreas dedicadas al cultivo de algodón, cacao, tabaco y de otros productos requeridos e introducidos por los españoles tales como la caña de azúcar o el arroz. No obstante, debido a la presencia de zonas montañosas que dificultan el desempeño de la agricultura, los conquistadores concibieron la ganadería como la mejor alternativa productiva que les permitiera aprovechar este territorio; en especial, aquellas áreas que contaban con pastizales naturales.

La cría de distintos tipos de ganado no sólo les proporcionaría alimento o productos para comerciar, sino también el medio de carga y transporte, indispensable, para la extracción de los recursos naturales y productos de esta parte de la Nueva España (Pavía, 2001). Así, las porciones bajas de la costa guerrerense fueron las primeras en registrar unidades productivas con orientación pecuaria y, consecuentemente, el desplazamiento de la población nativa hacia áreas serranas (Rubí y Pavía, op. cit.).

Por otro lado, la virtual exportación de los distintos productos novohispanos con demanda en la economía mercantil europea, así como la importación de aquellas semillas, materias primas o bienes con las que no se contaba en el continente americano impulsó la construcción de astilleros. Acapulco albergó a uno de ellos y se erigió como la terminal de la línea de navegación que conectaba la Nueva España con Asia. Durante la época virreinal, este puerto registró una actividad comercial significativa debido al arribo anual del galeón de Manila (Ibid.).

Así, los poblados situados en puntos intermedios del trayecto México-Acapulco también se beneficiaron, en particular Chilpancingo que comenzó a figurar como un asentamiento orientado al suministro de bienes y servicios para los viajeros que se desplazaban al puerto para adquirir las mercancías traídas por el galeón. Por su parte, Tepecoacuilco albergó a algunas casas mercantiles que erigieron a esa localidad como uno de los principales centros de intercambio comercial del territorio suriano (Garza, op. cit.). 


\section{El despunte económico-poblacional diferenciado (1700-1810)}

Es a partir del siglo XVIII cuando se registró una mayor afluencia de ibéricos hacia lo que hoy conforman las distintas regiones de Guerrero. La mayor cantidad de ellos llegó a la Tierra Caliente, atraídos por los yacimientos de Tetela y el aparente excedente de tierras para cultivar o criar ganado; pues, con frecuencia, argumentaban que los indígenas "poseían más tierras de las que podían cultivar" (Rubí y Pavía, op. cit.).

De esta manera, aconteció un significativo incremento en el número de haciendas agropecuarias y, de manera paralela, se agravó la disputa por la propiedad de la tierra, entre ambos grupos, en particular en la región citada, la Norte y Centro. Esto sería una de las principales causas de las revueltas que se gestarían en el siglo posterior (Ibid.).

En Taxco se intensificó la dinámica socioeconómica como resultado del auge minero que tuvo a principio del siglo (Pérez, 1996). Ese sitio, junto con Acapulco, eran los principales consumidores de la producción agropecuaria del resto del territorio. Dicha localidad también comenzó a atraer población no indígena, la cual se asentó, preferentemente, en torno al puerto ${ }^{4}$. Cerca de allí tuvo lugar uno de los principales latifundios de la entidad, la hacienda de San Marcos cuya producción servía para abastecer a la creciente población acapulqueña.

En la mayor parte del territorio guerrerense, la producción agropecuaria estaba orientada al consumo interno y se distribuía mediante los caminos vecinales que se caracterizaban por la sinuosidad y la presencia constante de rocas. Los caminos reales eran escasos; evidentemente, el de mayor relevancia fue aquel que comunicaba a la Ciudad de México con Acapulco, alrededor de él se articulaban otros más hacia los principales asentamientos tales como Taxco, Iguala, Chilapa o Tixtla.

La producción de manufacturas era mínima y poco diversificada (Rubí y Pavía, op. cit.). Tuvo lugar, sobre todo, en las regiones Norte, Centro y Tierra Caliente. Había sitios dedicados a la elaboración de azúcar, piloncillo, loza y/o prendas de algodón. Acapulco y Taxco eran los principales consumidores de estos productos. Así, por ejemplo, las localidades de Tlacotepec, Cutzio, Cutzamala y Asuchitlan se encargaban de abastecer

4 En diferentes obras que abordan el período de dominio hispano en Guerrero, los historiadores denominan población no indígena al conjunto humano conformado por españoles, negros, y asiáticos (llegados con el galeón de Filipinas); así como a los individuos resultantes de la mezcla de éstos y de ellos con la población nativa. 
de ropa a la creciente población taxqueña. También La Montaña destacó la producción de textiles (Pavía, op. cit.).

A fines del siglo, sólo Acapulco había adquirido la categoría de ciudad. El Centro fue la región que registró mayor cantidad de población no indígena, un total de 9033 personas. Le siguieron en importancia la Costa Chica (6 098), Acapulco (5 679), La Montaña (4 208), Tierra Caliente (3 972), Norte (2 230) y la Costa Grande (1 430) (Rubí y Pavía, op. cit.). En el territorio aún predominaba la población indígena. En ese sentido, es importante señalar que sólo subsistían amuzgos, mixtecos, tarascos, cuitlatecas, tlapanecas y nahuas (Ibid.).

\section{La inestabilidad político-social (1810-1869)}

La población que radicaba en el actual estado de Guerrero tuvo participación importante en el movimiento de independencia de México. Los sectores de la élite no favorecidos por el reformismo borbónico, grupos disgustados por la presión fiscal impuesta por la Corona y, principalmente, todos aquellos inconformes con el deterioro de su situación económica, empuñaron las armas y conformaron un importante bastión insurgente (Illades, op. cit.).

A las familias de los hacendados se sumaron los peones de las haciendas, mulatos no dispuestos a continuar con el pago de tributo y con el deseo de obtener la ciudadanía, así como distintas comunidades indígenas. El territorio fue sede de un número significativo de las campañas militares que emprendió José María Morelos; tras su muerte, personajes guerrerenses como Nicolás Bravo y Vicente Guerrero continuaron con la lucha armada.

La notabilidad político-militar de este último lo llevó a pactar con Agustín de Iturbide el fin de la guerra, el 24 de febrero de 1821. A pesar de ello, en los decenios subsecuentes, la inestabilidad político-social prevaleció en el territorio suriano debido a su continua participación en los distintos movimientos armados de la naciente nación mexicana y a los conflictos derivados de la conformación del estado de Guerrero (Ibid.).

Durante el segundo tercio del siglo XIX, Juan N. Álvarez, nacido en Atoyac, fue el personaje con mayor relevancia político-regional debido a su trayectoria militar y a su papel como interlocutor entre el gobierno nacional y los grupos locales. Esa situación le dio la pauta para que consolidara un cacicazgo de tipo paternalista. Además, junto con Bravo, impulsó 
la creación del estado, la cual se concretó, en 1849, con porciones de México, Michoacán y Puebla ${ }^{5}$ (McGowan, 2004).

En términos productivos, un segmento considerable de guerrerenses desempeñaba labores agropecuarias. La siembra de maíz para autoconsumo se practicó en la mayor parte del territorio (Ibid.). El cultivo de hortalizas, legumbres, tabaco y caña de azúcar fue el soporte del comercio local e interregional. Únicamente, la producción de algodón de La Montaña y las costas estuvo orientada a los mercados nacionales e internacionales ${ }^{6}$. Cobró relevancia la exportación de este producto hacia Estados Unidos, durante la guerra civil en aquel país.

Poca población se ocupó en la elaboración de manufacturas. Además, esa actividad no presentó modificaciones significativas respecto al siglo anterior (Pavía, op. cit.). En cuanto a la minería, ésta se trabajó en Taxco y, en menor proporción, en la Tierra Caliente, aunque con menos rendimientos que durante el dominio español (Figura 4).

Finalmente, Acapulco, a pesar de la suspensión del comercio con Filipinas, fungió como uno de los principales puertos que posibilitaron el intercambio comercial con otros sitios del país y con el extranjero. Ese punto suriano registró el arribo de buques ingleses, italianos, franceses, colombianos, chilenos y peruanos que garantizaron una importante derrama económica no sólo para los acapulqueños, sino también para los habitantes del Centro, Costa Chica y Costa Grande que acudían a emplearse o vender sus productos allí (Ibid.).

5 Al crearse el estado de Guerrero, Iguala fungió como la capital provisional sólo durante tres meses, ya que el 21 de enero de 1850, se trasladaron los poderes a Tixtla, sitio en el que quedó establecida la primera capital constitucional. Finalmente, en 1870, se decretó su cambio a la ciudad de Chilpancingo, donde permanece hasta la actualidad (Pavía y Salazar, op. cit.).

6 Tal actividad dio la pauta para que, a lo largo de la segunda mitad del siglo XIX, se fortalecieran distintos dominios territoriales, los cuales se vieron favorecidos por la privatización de las tierras corporativizadas por comunidades indígenas y/o la iglesia, ya que tal acción permitió a las autoridades obtener ingresos mediante el cobro de impuestos. De esta manera, en el estado de Guerrero, al igual que otras porciones del territorio nacional, se intensificó la concentración de extensas áreas agrícolas, la mayoría de las ocasiones las más productivas, en manos de unas cuantas familias tales como los Pérez, en la Tierra Caliente; los Miller, en la Costa Chica o los Fernández, en la Costa Grande. Por lo general, éstos tenían un significativo control no sólo sobre las tierras, sino también sobre la fuerza productiva y el comercio de la producción (Ravelo y Bustamante, 1998). Asimismo, durante el porfiriato tuvieron relevancia varios latifundistas ausentistas que se apropiaron de considerables extensiones del territorio estatal con la finalidad de explotar los recursos forestales y minerales para cuando mejoraran las condiciones, sobre todo aquellas relacionadas con las vías de comunicación. Destacaron, el latifundio de Lewis Lamm, en Tlapa, así como aquel perteneciente a la compañía The Guerrero Land Timber, en la Costa Grande (Ibid.). 
La inasequible modernización económico-productiva (1869-1910)

Durante este período, una parte considerable de las acciones del gobierno guerrerense se concentró en buscar capitales estadounidenses y europeos que impulsarán la agricultura, la minería y la construcción de vías de comunicación, pues la falta de caminos y/o las malas condiciones en las que estaban era una de las principales limitantes para el desarrollo de las actividades productivas en la entidad (Pavía y Salazar, 1998).

Hacia las postrimerías del siglo, se observó un considerable incrementó en la apertura de caminos. A ello favoreció el Decreto Estatal 34, emitido en 1879, que obligó a todo varón, cuya edad oscilará entre los 18 y los 50 años, a contribuir con tres días de jornada anuales para abrir y reparar los caminos (Miranda, 1994). También se emprendió el estudio de las características del cauce del río Balsas para evaluar la posibilidad de hacerlo navegable.

Lo anterior tuvo como resultado el establecimiento de la ruta que comunicó a la localidad de Pezuapa (Arcelia) con la porción del Balsas Norte (Cocula), esta última además quedó articulada con el centro del país, a través de las vías ferroviarias. A la postre, las embarcaciones ampliaron su itinerario hasta los municipios de Coyuca de Catalán y la hacienda de Las Balsas (Coahuayutla) (Pavía y Salazar, op. cit.). 
Figura 4. Guerrero: características socioeconómicas en el siglo XIX

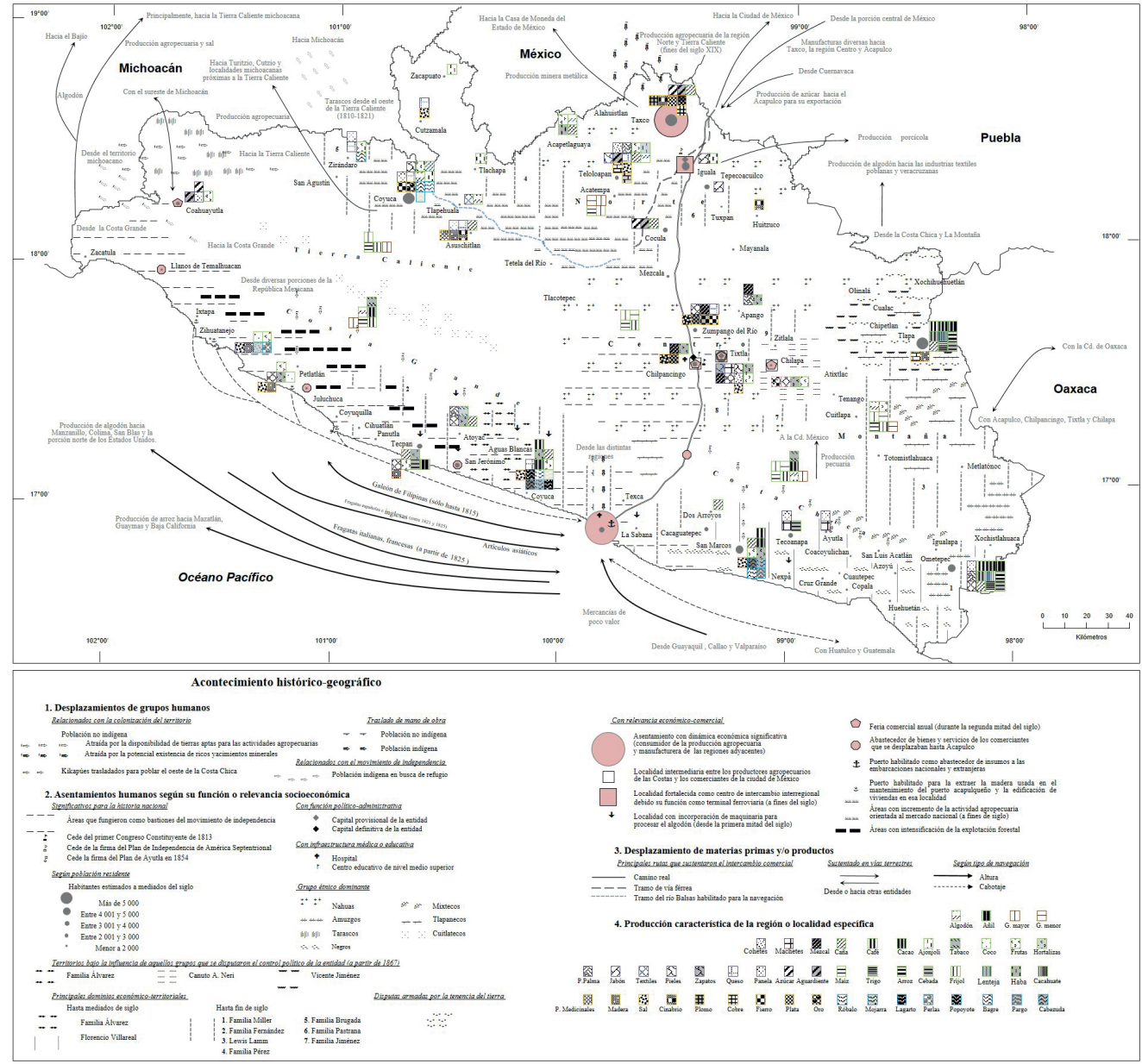

Fuente: elaborado con base en Secretaría de Gobernación, op. cit.; Miranda, op. cit.; Pérez, op. cit.; Pavía y Salazar, op. cit.; Rubí y Pavía, op. cit.; Illades, op. cit., Pavía, op. cit.; McGowan, op. cit.

Por otra parte, los elevados costos de construcción debido al predominio de áreas montañosas, así como las constantes revueltas armadas que se gestaban en el territorio guerrerense, el escaso número de habitantes (la mayoría pobres), la significativa dispersión de los asentamientos humanos y de las distintas unidades de producción agropecuaria, fueron algunos de los principales factores que ocasionaron que el ferrocarril sólo llegará a la porción septentrional del estado. 
De esta manera, en lo sucesivo, las regiones Norte y Tierra Caliente tuvieron un incremento en su producción agrícola, pues contaron con vías de comunicación para desplazarla a distintos puntos del mercado nacional. Iguala registró expansión comercial y se convirtió en un importante centro de intercambio regional. Allí también comenzaron a asentarse algunas industrias aceiteras y jaboneras (Illades, op. cit.).

En el resto de la entidad, la actividad manufacturera se desarrolló en talleres artesanales, a pesar de que las autoridades estatales trataron de incentivar su evolución. Por ejemplo, entre 1869 y 1893, el gobierno guerrerense exentó del pago de impuestos, hasta por diez años, a toda actividad fabril que se estableciera en el estado. La actividad minera tampoco logró despuntar, los trabajos de campo, subsidiados por el gobierno, sólo tuvieron como principal resultado el descubrimiento de importantes yacimientos carboníferos en el área comprendida entre Zumpango-Chilpancingo-Llanos de Huiziltepec y Petaquillas (Pavía y Salazar, op. cit.).

Por lo tanto, los intentos de modernización económica-productiva sólo alcanzaron pocos sitios del territorio guerrerense. Además, desde fines del siglo XIX, la inestabilidad socio-política repuntó en la entidad y los potenciales inversionistas optaron por orientar sus capitales hacia entidades menos conflictivas (Ibid.).

El inicio de los proyectos turísticos (primera mitad del siglo XX)

Las actividades económicas primarias de subsistencia fueron desempeñadas por la mayor parte de los guerrerenses. A principio de los treinta, hubo algunos intentos de modernización de la actividad agrícola, sobre todo, en el área norte de la entidad, así en los valles de Iguala y Cocula se comenzó a incorporar tractores y camiones para el transporte de la producción. Años más tarde, aquí también comenzarían a emplearse las primeras rastras, empacadoras de forrajes y desgranadoras de la entidad (Ravelo y Bustamante, 1998).

De igual forma, es partir de esa época cuando se intensifica la explotación de los bosques, principalmente, en porción serrana del Centro y la Costa Grande. En esa última región, dos decenios después, la extracción de madera fue monopolizada por las empresas como Forestal Cacho de Oro; Maderera de Guerrero; La Providencia y Anexas; entre otras. El territorio contaba sólo con unas cuantas fábricas asentadas, principalmente, 
en la región Norte, Acapulco y Centro. La mayoría de ellas se ocupó de la producción de hielo, refrescos y la purificación de agua (Ibid.).

En materia de vías de comunicación, el acontecimiento de mayor relevancia fue la conclusión de la vía que comunicó a la Ciudad de México con el puerto de Acapulco, en 1927 (Illades, op. cit.). Con ello, inició la afluencia de algunos viajeros que se aventuraban a visitar el puerto; paralelamente, emergieron los primeros hoteles en aquel sitio $^{7}$. De manera gradual, tanto el gobierno federal como el estatal pusieron en marcha distintas acciones encaminadas a habilitarlo como destino turístico.

Durante el sexenio del presidente Lázaro Cárdenas (1934-1940), se conformó un equipo de expertos para proyectar el desarrollo urbano del puerto, se construyeron edificios federales y se otorgó la concesión a la empresa Eureka S.A. para introducir el drenaje y alcantarillado, infraestructura indispensable para los hoteles y fraccionamientos que se comenzaban a construir, en el área circundante a la bahía (Ravelo y Bustamante, op. cit.). Además, el gobierno federal incentivó el arribo de inversiones nacionales y extranjeras mediante las facilidades concedidas a todos los proyectos relacionados con el impulso del turismo.

El financiamiento de infraestructura y servicios de ese naciente centro vacacional se intensificó durante el período presidencial de Manuel Ávila Camacho (1940-1946), ello se debió a la iniciativa denominada "peso contra peso", mediante la cual el gobierno mexicano se comprometió a aportar la misma cantidad que la que aquellos particulares invirtieran en el desarrollo turístico de Acapulco (Ramírez, op. cit.).

El gobierno de Miguel Alemán Valdez (1946-1952) concretó la expansión urbano-turística del puerto. Autorizó la expropiación de catorce ejidos, sobre ellos más tarde se edificarían lujosos hoteles y fraccionamientos como Las Brisas. Asimismo, en 1945, se creó la Junta Federal de Mejoras Materiales orientada a culminar los trabajos de alumbrado y saneamiento. Se trazaron las calles indispensables para la urbanización de

$7 \quad$ El incremento en la infraestructura hotelera también estuvo relacionado con el cierre de algunos destinos turísticos europeos, durante la Segunda Guerra Mundial. Los estadounidenses contemplaron al puerto de Acapulco como una alternativa para vacacionar. Asimismo, el fin del conflicto armado también favoreció a esta localidad, ya que fue seleccionada junto con La Habana (Cuba) como los lugares idóneos para la recuperación de los excombatientes estadounidenses, una situación que se repitió al culminar la guerra de Corea (Ramírez, op. cit.). 
la bahía, se trasladó el aeropuerto fuera de ésta y se inició la construcción de la autopista México-Acapulco (Ibid.).

De esa forma, la actividad turística empezó a destacar como la principal actividad de la entidad; para el decenio de los cuarenta, $25 \%$ de los visitantes eran extranjeros atraídos por los bajos costos, debido a la devaluación de la moneda nacional. La actividad turística acapulqueña comenzó a demandar una cantidad significativa de mano de obra, esto ocasionó la migración de trabajadores de otras regiones de Guerrero e incluso de otras entidades de la República Mexicana (Illades, op. cit.) (Figura 5).

El despunte de los centros turísticos (a partir de la segunda mitad del siglo $X X)$

\section{Acapulco}

A partir de los cincuenta, el puerto de Acapulco se erigió como el lugar para vacacionar en México. Eso se debió al mejoramiento de las carreteras que articulaban al puerto con la capital del país, así como a la apertura de un aeropuerto internacional en aquella localidad, en 1964. Éste facilitó el arribo de jets que transportaban una mayor cantidad de personas, además las aerolíneas internacionales empezaron a ofrecer vuelos directos y con costos bajos para aquellos que viajaban en grupo. 
Figura 5. Guerrero: características socioeconómicas contemporánea

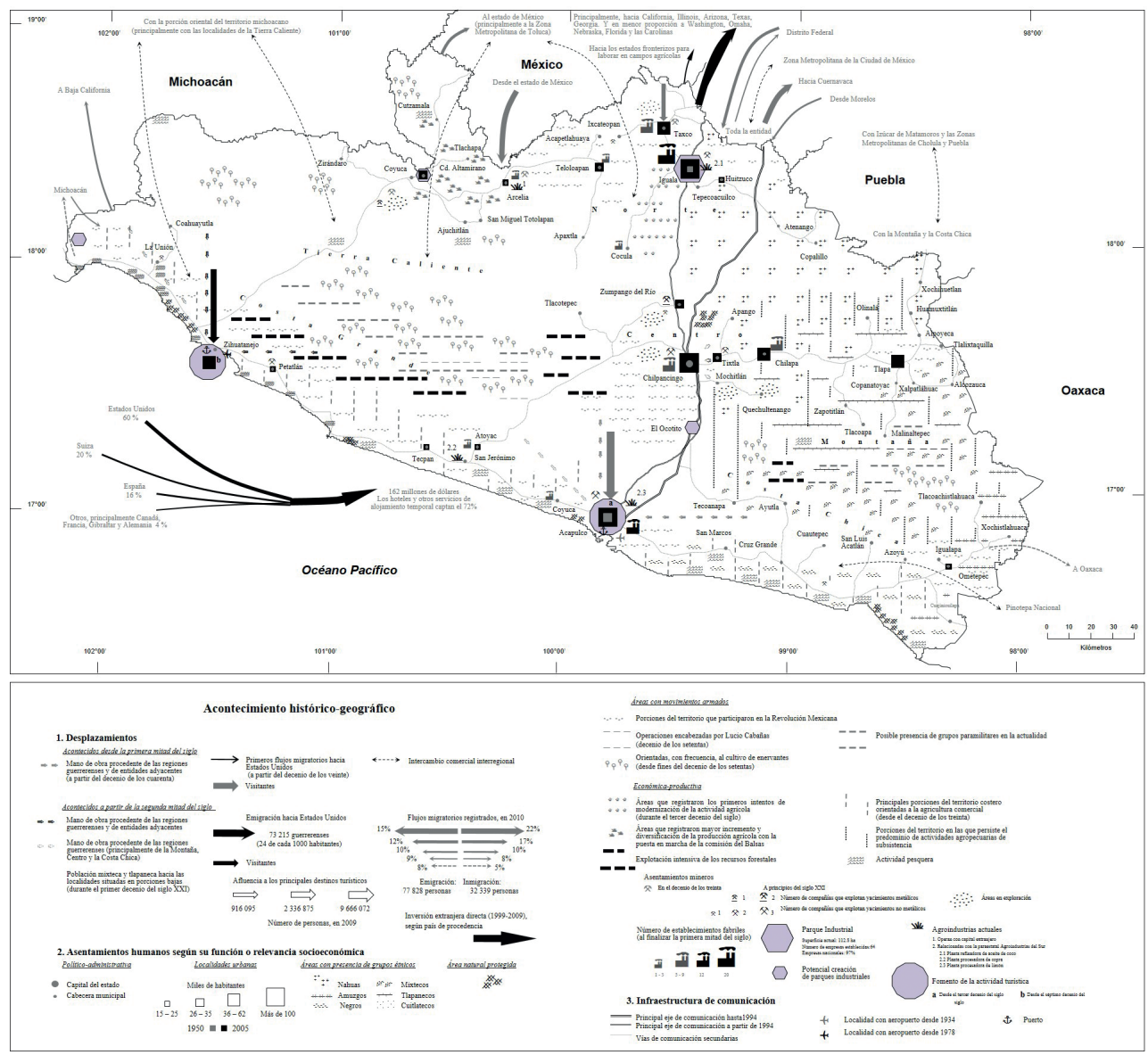

Fuente: elaborado con base en Secretaría de Gobernación, op. cit.; Juárez, op. cit.; Ravelo y Bustamante, op. cit.; Bartra, 2000; Bustamante, León y Terrazas, 2006; Servicio Geológico Mexicano, 2008; CONAPESCA, 2009; Gobierno del estado de Guerrero, 2010a, INEGI, 2015 y Secretaría de Economía, 2015.

Durante los setentas, el flujo de turistas que arribó a Acapulco se incrementó considerablemente: en 1970 recibió 1003800 personas y 2458000 , en 1978. Tal aumento se vio reflejado en la proliferación de hoteles y habitaciones que ofertaba este punto de la entidad. En él, las primeras cadenas de hospedaje que inauguraron una propiedad fueron Hyatt, Marriot, Western, Pierre, Sheraton y Americana Hotels (filial de American Airlines). 
El aumento en el número de hoteles e infraestructura indispensable para desempeñar las actividades turísticas transformó el paisaje en la localidad guerrerense. Entre 1950 y 1980, la ciudad creció de 1250 a 2726 hectáreas. Se expandió sobre la zona de pie de monte y áreas montañosas (con altitud superior a $225 \mathrm{~m}$ ) alrededor de la bahía, así como al noroeste de la localidad (Valenzuela y Coll-Hurtado, 2009).

La etapa de mayor prestigio internacional que vivió Acapulco durante el decenio de los setentas se modificó al inicio de los ochentas, debido a problemas ambientales, sociales y urbanos. En 1980, se registró una reducción mayor al 40\% del total de visitantes extranjeros que tuvo en 1978. El descenso continuó los dos años siguientes y, en lo sucesivo, el flujo de turistas presentó un incremento lento con retrocesos mínimos.

No obstante, la disminución en la cantidad de visitantes extranjeros ha sido constante hasta llegar al $1.5 \%$ del total de vacacionistas. A diferencia de lo ocurrido en decenios anteriores, ha tomado relevancia la llegada de turistas nacionales pertenecientes a los estratos socioeconómicos medio y bajo. Esto ha dado pauta a la multiplicación de pequeños y medianos negocios con propietarios locales y/o trabajadores independientes (Ibid.).

Acapulco ha ejercido atracción de capitales nacionales y extranjeros. Un hecho que ha repercutido en la formación y consolidación de grupos de empresarios que, al amparo de la clase política local y federal, se han apropiado de considerables extensiones territoriales para desarrollar proyectos inmobiliarios, así como de la dotación preferente de infraestructura urbana o de la publicidad indispensable para promover la actividad turística acapulqueña.

El dinamismo de ésta ha propiciado el desarrollo y expansión de sus tres zonas turísticas (Tradicional, Dorado y Diamante). En 1998, Acapulco contó con una inversión de 1209 millones de dólares en diversos proyectos turísticos. De acuerdo con la Secretaría de Turismo, esto se debe a que los inversionistas nacionales tienen predilección por los destinos de playa consolidados del país (Ibid.).

Durante el decenio anterior, éstos recibieron 11607 millones de dólares ( $48 \%$ del total nacional). En dicho período, el estado de Guerrero atrajo la mayor parte de ese monto, esto es 2625 millones de dólares $(22.6 \%$ del total). De esa inversión, Acapulco concentró el 89.0\%, Ixtapa-Zihuatanejo $6.5 \%$ y la región Norte $4.5 \%$ (Gobierno del estado de Guerrero, 2010b). 
Acapulco aún es el destino del litoral mexicano que capta más visitantes de origen nacional. Por esta razón, la actividad económica preponderante corresponde al sector terciario. La rama de servicios reúne la mayor proporción de la PEA (73\%). Destaca la población ocupada en hoteles, restaurantes, transporte y comunicaciones, servicios financieros, seguros, bienes raíces, servicios bancarios, servicios comunales, sociales y personales. En estas actividades se emplean alrededor de 75 mil personas en 10,890 empresas (Ibid.).

\section{Ixtapa-Zihuatanejo}

En los últimos cuatro decenios, los gobiernos federal y estatal han concebido al turismo como una actividad fundamental para dinámica socioeconómica de Guerrero. Por tal motivo, se han puesto en marcha programas y acciones relacionadas con la consolidación y diversificación de esta actividad económica. En México, Ixtapa-Zihuatanejo fue el primer complejo turístico nacional financiado por el Banco Mundial.

El gobierno mexicano presentó la solicitud ante dicho organismo en abril de 1969 y ésta fue aprobada dos años después. Simultáneamente, el Banco de México creó el fideicomiso denominado Fondo de Promoción e Infraestructura Turística (INFRATUR). Asimismo, la promulgación de la Ley de Fomento Turístico, en 1974, incentivó el inicio del desarrollo de este centro de playa que se constituyó en el segundo núcleo turístico impulsado por FONATUR, con un costo inicial de 48 millones de dólares (Ibid.).

A fines de los sesentas, en Zihuatanejo había trece hoteles que ofertaban un total de 133 cuartos. Para 1974, la localidad disponía de 300 habitaciones; un año más tarde, el sitio ya se promocionaba como un centro vacacional orientado al turismo nacional y extranjero, con 750 cuartos. En 1988, Ixtapa poseía 2660 y Zihuatanejo 292 de ellos. Un decenio después se contabilizó 64 hoteles con 4433 habitaciones. De ellos, 50 se situaron en Zihuatanejo y catorce en Ixtapa. Ésta localidad presentó 2298 habitaciones con categoría de cinco estrellas y 961 de cuatro estrellas.

En contraste, Zihuatanejo sólo contó con 99 y 269 cuartos pertenecientes a cada una de las clases anteriores. Ambos sitios tenían más de 50 restaurantes, diversos centros nocturnos, dos clubs de golf, boutiques, joyerías o tiendas que expenden souvenirs (López, 2000). De acuerdo con el Programa de Desarrollo Integral Sustentable de la Costa Grande, 
el fomento de la actividad turística, en esta porción de Guerrero, ha buscado desarrollar y estimular la inversión en aquella infraestructura diseñada para atraer, principalmente, a visitantes con altos ingresos económicos (Gobierno del estado de Guerrero, 2010a).

Durante los noventas, FONATUR comercializó terrenos, megaproyectos como Marina Ixtapa y Punta Ixtapa, los negocios Azul Ixtapa y Porto Ixtapa, así como distintos activos por un monto de 31.5 millones de dólares. También, durante dicho período, ese organismo, en colaboración con otras instituciones, se encargó del financiamiento de diversas obras urbano-turísticas. Entre 1994 y 1998, Bancomext aportó 158 millones de dólares para la promoción de nueve proyectos turísticos en el estado, de los cuales 56 millones estuvieron destinados a Ixtapa-Zihuatanejo. En 1999, en Ixtapa se invirtieron, aproximadamente, 2.1 millones de dólares en infraestructura turística.

En la actualidad, Ixtapa-Zihuatanejo cuenta con 145 hoteles y 6206 habitaciones (35.7 y $24.5 \%$ de total estatal, respectivamente) y registró una afluencia de 590199 visitantes, 75\% de origen nacional y $25 \%$ extranjero (Gobierno del estado de Guerrero, 2010b). Aunque la derrama económica relacionada con la actividad turística de este sitio de Guerrero es significativa para el PIB estatal, el impacto de estos recursos en la región es mínimo porque una proporción considerable de los ingresos que se obtienen por vía fiscal son transferidos al gobierno federal. Asimismo, en los últimos cuatro decenios, la región se ha visto afectada por el deterioro ambiental y contaminación derivada de la puesta en marcha de proyectos turísticos sin planeación.

\section{Discusión de resultados}

Este trabajo compendia un conjunto de acontecimientos geo-históricos, en torno al origen de los desequilibrios económico-regionales del estado de Guerrero. Esos hallazgos cognoscitivos son relevantes debido a las investigaciones escasas en la materia. A diferencia de lo expuesto en la literatura existente, en este documento se hace énfasis en las distintas interrelaciones económicas que mantienen los espacios guerrerenses y se identifican los procesos socio-territoriales que dieron lugar a ellas.

El análisis de la realidad espacial demanda evaluar la acción que ejercen múltiples factores, los cuales actúan de manera “...interactiva, 
reforzándose o compensándose mutuamente. ...la influencia de las condiciones naturales o ecológicas, las herencias del pasado que aún se hace presente en ocasiones, el volumen y características de la población, el sistema de relaciones sociales, las pautas culturales dominantes, o la organización política institucional serán las principales razones explicativas de la situación actual..." (Méndez, 1997).

Asimismo, la dialéctica globalización-territorialidad, demanda ponderar la interacción de múltiples factores que reconfiguran las regiones (Boisier, 1998). Pues “...la economía global ha llegado a ser un mosaico de regiones económicas desplegándose a través de múltiples jurisdicciones políticas", con ello se "está contribuyendo a redibujar el mapamundi de la geografía política real mediante el debilitamiento de la noción tradicional de estado nacional y mediante el paralelo fortalecimiento de los cuasiestados supranacionales y subnacionales" (Boisier, 1994).

Los patrones económico-regionales de Guerrero reflejan tanto la impronta de actividades productivas acaecidas en períodos precedentes como de la dinámica socio-territorial contemporánea. Por lo tanto, para la explicación holística de las formas de ocupación económica identificadas en la entidad, es fundamental tomar en cuenta la evolución geo-histórica de la gama de actividades que han dotado de heterogeneidad socioeconómica al territorio guerrerense, lo cual da pauta para robustecer los aportes de especialistas como Garza (op. cit.), Juárez (op. cit.) y Ortiz (op. cit.).

En particular, los resultados de investigación advierten que: 1) las diferencias regionales son significativas debido a la incorporación desigual de espacios guerrerenses a la vida económica estatal, nacional e internacional; 2) existe un nexo importante entre la dinámica socioeconómica de cada uno de ellos y su problemática ambiental; 3) se requieren alternativas político-económicas congruentes con los retos sociales y económicos derivados de lo anterior; y 4) en particular, la construcción de mecanismos de coexistencia y regulación pacífica de los conflictos sociales potenciales que pudiesen surgir.

\section{Conclusiones}

Los desequilibrios regionales guerrerenses emergieron con el arribo de grupos de conquistadores (mexicas y, a la postre, españoles) y la ocupación de las áreas dotadas de recursos naturales o características físicas 
de su interés. La presencia de zonas favorables para el desempeño de actividades agropecuarias, y la existencia de yacimientos minerales, impulsó, progresivamente, el poblamiento y cierto crecimiento económico de algunos asentamientos humanos en las regiones Norte, Centro, Tierra Caliente y el litoral, en especial, en la Costa Grande y el puerto de Acapulco.

Sin embargo, es a lo largo de la segunda mitad del siglo XX cuando se agudizan las disparidades territoriales por la consolidación de Acapulco e Ixtapa-Zihuatanejo como centros turísticos ya que, para lograrlo, los gobiernos nacional y estatal han invertido una parte substancial del erario en la creación de infraestructura, indispensable, para el desplazamiento, hospedaje y atención de los visitantes (García, op. cit.).

El impulso y fortalecimiento de esos destinos turísticos ha originado que las circunscripciones involucradas dependan, mayoritariamente, de recursos generados en otros territorios; el número empleos y los ingresos económicos fluctúan según la temporada alta o baja de afluencia de visitantes. Pese a ello, el gobierno federal y estatal incentiva el arribo de turistas a más localidades costeras y lugares, alternativos a los destinos de sol y playa, distribuidos en las siete regiones de Guerrero.

En contraste, la modernización del sector primario y secundario no ha tenido lugar por la falta de inversiones públicas y privadas, a pesar de que la entidad cuenta con diversas áreas con características tanto físicas como socioeconómicas que podrían favorecer la creación de distintos proyectos productivos y, por lo tanto, atenuar la falta de alternativas laborales y los problemas sociales asociados con ella.

La entidad tiene potencial minero significativo, pero la explotación de los yacimientos ha estado a cargo de compañías extranjeras, en especial canadienses, quienes se quedan con la mayor parte de las utilidades obtenidas, en detrimento de los ejidatarios a los que se les despoja de sus predios y del entorno físico que se contamina. Si bien se generan empleos en los lugares donde se asienta esa actividad económica, es mayor la expoliación que registra la población local, en relación con los beneficios que obtienen.

Lo anterior permite vislumbrar que el terciario se mantendrá como el sector más importante en Acapulco, Zihuatanejo de Azueta y Chilpancingo. Así, el comercio y los servicios podrían consolidarse como la principal fuente de trabajo de la PEA guerrerense; en demarcaciones que albergan a las ciudades guerrerenses, en las jurisdicciones de la costa que se ofertan a 
los turistas e incluso en aquellos espacios que reportan actividades agropecuarias con bajos rendimientos; pues, ante tal situación, la población opta por auto-emplearse en el comercio informal.

\section{Referencias}

Aguilar, R. (2013). Niveles de asimilación económica del territorio en Baja California Sur. Tesis de licenciatura en Geografía. Facultad de Filosofía y Letras, UNAM. México. (pp. 189)

Aponte, E. (2006). La geohistoria un enfoque para el estudio del espacio venezolano desde una perspectiva interdisciplinaria. En: Scrita Nova, Vol. X, Núm. 218 (08). 2006

Bartra, A. (2000). Guerrero bronco. Campesinos, ciudadanos y guerrilleros en la Costa Grande. Distrito Federal, México: Ediciones Era

Boisier, S. (1998). El desafío territorial de la globalización. Reflexiones acerca del sistema Chileno. En: Economía, Sociedad y Territorio, Vol. I, núm. 4, 1998. (pp. 755-777)

Boisier, S. (1994). Postmodernismo territorial y globalización: regiones pivotales y regiones virtuales. En: Ciudad y Territorio, Estudios Territoriales, Vol. II. núm. 102, 1994. (pp. 1-22)

Braudel, F. (1982). La Mediterranée a la époque de Philippe II. Paris, Francia: PUF

Bustamante, T., León, A. y Terrazas, B. (2000). Reproducción campesina, migración y agroindustria en Tierra Caliente, Guerrero. Distrito Federal, México: Plaza y Valdez Editores

Commons, A. (1985). Gestión y nacimiento de un estado: Guerrero. En: Investigaciones Geográficas, Boletín núm. 15, 1985. (pp. 119-153)

CONAPESCA (2009). Atlas de localidades pesqueras: Guerrero. Distrito Federal, México: Comisión Nacional de Acuacultura y Pesca

CONEVAL (2017). Medición de la pobreza 2010. Resultados a nivel municipal. Recuperado de: http://www.coneval.gob.mx

García, N. (2011). Los grados de asimilación económica del estado de Guerrero, a fines del siglo XX. Tesis de doctorado en Geografía. Facultad de Filosofía y Letras, UNAM. México. (pp. 186)

García, N. (2007). Cambios en los tipos de asimilación económica del estado de Guanajuato, entre 1950 y 2000. Tesis de maestría en Geografía. Facultad de Filosofía y Letras, UNAM. México. (pp. 107) 
Garza, G. (2009). Historia de una acentuada desarticulación territorial: el estado de Guerrero. En: Investigaciones Geográficas, Boletín núm. 68, 2009. (pp. 116-130)

Gerhard, P. (1986). Geografía Histórica de la Nueva España, 15191821. Distrito Federal, México: Instituto de Investigaciones Históricas, UNAM

Gobierno del estado de Guerrero (2015). Municipios del estado de Guerrero. Recuperado de: http://www.guerrero.gob.mx/?P=municipios

Gobierno del estado de Guerrero (2010a). Programa de desarrollo integral sustentable, Costa Grande. Gobierno del estado de Guerrero. Recuperado de: http://www.guerrero.gob.mx/pics/art/articles/6121/file. PDF_costa_grande.pdf

Gobierno del estado de Guerrero (2010b). Programa sectorial de turismo 2005-2011. Secretaría de Fomento Turístico del Gobierno del estado de Guerrero. Recuperado de: http://www.guerrero.gob.mx/?P=reada rt\&ArtOrder $=$ ReadArt\&Article $=952$

Illades, C. (2000). Breve historia de Guerrero. Distrito Federal, México: Fondo de Cultura Económica

INEGI (2017). Sistema Estatal y Municipal de Base de Datos. Recuperado de: http://sc.inegi.org.mx/cobdem/

Juárez, M. C. (1998). Los centros de comercio en el estado de Guerrero. En: Investigaciones Geográficas, Boletín núm. 37, 1998. (pp. 81-97)

Levy, J. (1997). Europe. Une géographie. Paris, Francia: En: Hachette

López, H. (2000). El turismo como factor de desarrollo regional. El caso de Ixtapa-Zihuatanejo. Facultad de Economía, UNAM. México. (pp. 122)

McGowan, G. L. (2004). La separación del sur o cómo Juan Álvarez creó su estado. Toluca, México: El Colegio Mexiquense

Méndez, R. (1997). Geografía Económica. La lógica espacial del capitalismo global. Barcelona, España: Editorial Ariel

Miranda, E. (1994). Economía y comunicaciones en el estado de Guerrero, 1877-1910. Morelia, México: Instituto de Investigaciones Históricas, Universidad Michoacana de San Nicolás de Hidalgo

Miranda, O. (2011). Dinámica temporal de las actividades económicas en el estado de Chihuahua: México. En: Revista Complutense de Historia de América, vol. 37, 2011. (199-220) 
Ortiz, M. I. (1998). Distribución espacial de la población en el estado de Guerrero 1990. En: Investigaciones Geográficas, Boletín núm. 37, 1998. (pp. 71-80)

Pavía, M. T. (2001). Anhelos y realidades del sur en el siglo XIX: creación y vicisitudes del estado de Guerrero, 1811-1867. Tesis de Maestría en Historia de México. Facultad de Filosofía y Letras, UNAM. México. (pp. 539)

Pavía, T. y Salazar, J. (1998). Historia general de Guerrero. Vol. III. Distrito Federal, México: Instituto Nacional de Antropología e HistoriaGobierno del estado de Guerrero

Pérez, L. (1996). Minería y sociedad en Taxco durante el siglo XVIII. Distrito Federal, México: Departamento de Historia, Universidad Iberoamericana

Propin, E. (2003). Teorías y métodos en Geografía Económica. Distrito Federal, México: Universidad Nacional Autónoma de México

Quiroz, H. C. (1998). Las mujeres y los hombres de la sal. Un proceso de producción y reproducción cultural en la Costa Chica de Guerrero. Tesis de Doctorado en Antropología. Facultad de Antropología, Universidad Iberoamericana. México. (pp. 414)

Ramírez, J. M. (1986). Turismo y Medio Ambiente. El caso Acapulco. En: Cuaderno divisional, núm. 4, 1986. (pp. 479-512)

Ravelo, R. y Bustamante, T. (1998). Historia general de Guerrero. Vol. IV. Distrito Federal, México: Instituto Nacional de Antropología e Historia-Gobierno del estado de Guerrero

Reyna, R. M. (2009). La cultura Mezcala y el Templo Mayor. Instituto Nacional de Antropología e Historia. Recuperado de: http://www. templomayor.inah.gob.mx/Mezcala/index_mezcala.html

Rubí, R. y Pavía, E. (1998). Historia General de Guerrero. Vol. II. Distrito Federal, México: Instituto Nacional de Antropología e Historia-Gobierno del estado de Guerrero

Santos, M. (1979). Economía espacial. Críticas y alternativas. Sao Paulo, Brasil: Hucitec

Secretaría de Economía (2015). Sistema Mexicano de Promoción de Parques Industriales. Recuperado de: http://www.contactopyme. gob.mx/parques/intranets.asp 
Secretaría de Gobernación (1988). Enciclopedia de los municipios de México: Estado de Guerrero. Distrito Federal, México: Secretaría de Gobernación

Servicio Geológico Mexicano (2008). Panorama minero del estado de Guerrero. Panorama minero de los estados. Distrito Federal, México: Servicio Geológico Mexicano

Valenzuela, E. y Coll-Hurtado, A. (2009). La construcción y evolución del espacio turístico de Acapulco (México). En: Anales de Geografía, Vol. 30, núm.1. 2009. (pp. 163-190) 
